\title{
Business Process Monitoring: BT Italy case study
}

\author{
Giorgio Rimini ${ }^{1}$, Paolo Roberti ${ }^{2}$ \\ ${ }^{1}$ British Telecom, Italy, Giorgio.rimini@bt.com \\ ${ }^{2}$ Business Integration Partners, Italy, Paolo.Roberti@mail-bip.com
}

\begin{abstract}
This paper presents the case study of BT Italy, which has implemented a performance dashboard to monitor business processes to deliver customer services. Top Management had a punctual view of the business processes, performance, such as Order Acquisition, Order delivery. Nevertheless, it wanted to enhance the end-to-end view to take actions improving the customer experience and reducing the lead time. The project objective has been to build a model to monitor the performance of customer services business processes, such as from customer's service request to service delivery and bill. Higo has been the main framework to define and select key performance indicators. The first part of the paper presents the BT scenario, the second part describes the performance monitoring model and the performance dashboard. The last paragraph presents the expected benefits and the conclusion of the case study.
\end{abstract}

Keywords: Business Process Management, Key Performance Indicators, Performance dashboard, Higo.

\section{Introduction}

Competition in the Italian Telco industry is getting stronger. Operators are struggling to acquire new customers and retain existing ones. It is crucial to design business processes to improve the customer experience and to increase revenue productivity. Moreover, Top Management must be able to monitor timely business processes performance and take necessary actions to steer business results.

This paper presents the case study of BT Italy, which has implemented a performance dashboard to monitor business processes to deliver customer services. The first part of the paper presents BT's scenario, the second part describes the performance monitoring model and the performance dashboard. The last paragraph presents the conclusion of the case study. 


\section{Framework}

As competition gets stronger, companies struggle to maintain business competitiveness. Management theory suggests that business competitiveness does not come only from pure financial performances, but from a combination of financial, quality and service performance. Performance needs to take in account all company stakeholders, which Edward Freeman defines "Those groups without whose support the organization would cease to exist".

Motta suggests trough the Higo grid to consider the point of view of the three stakeholders: Management, Customer and Worker. This grid fits BT Italy needs to monitor performance better than the Balanced Scorecard which considers mainly the management's point of view.

Below is represented an example of the Higo grid.

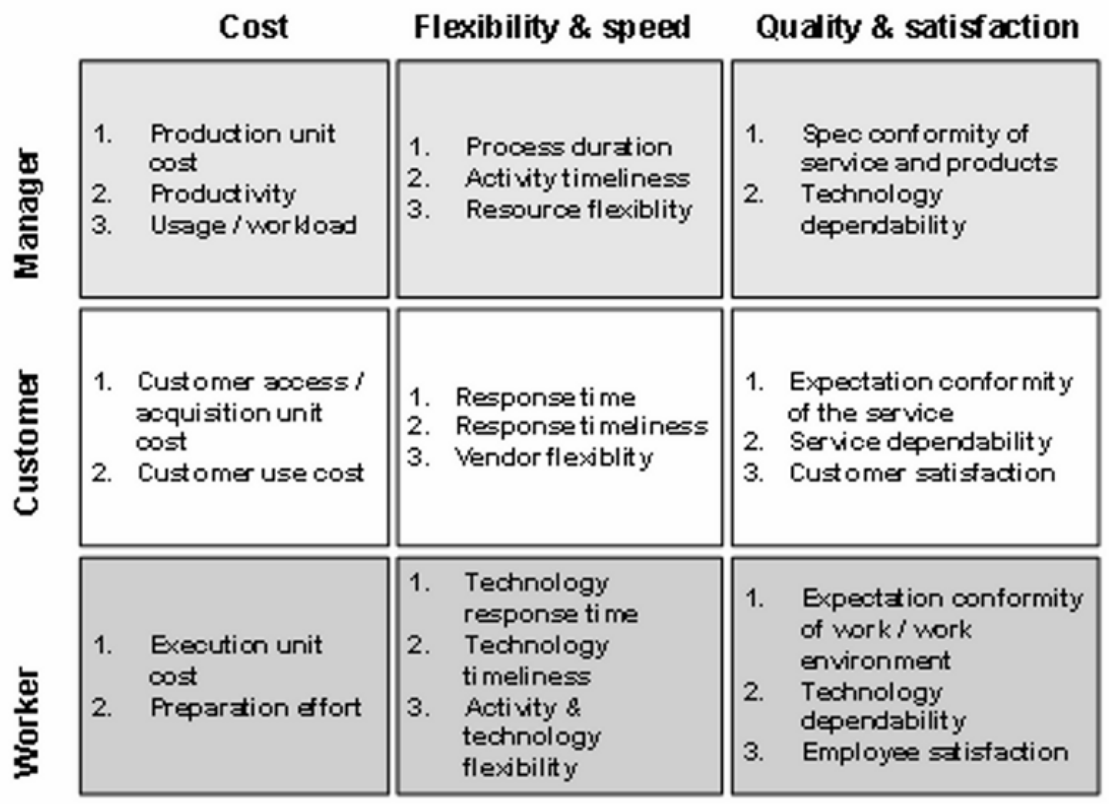

Fig. 1. Higo Grid

Parmenter (2007) suggest a 12-step model to select and implement KPIs:

1. Senior Team Management commitment

2. Establishing a "winning KPI" project team

3. Establishing a "just do it" culture

4. Setting a holistic KPI development strategy

5. Marketing KPI system

6. Identify organization-wide critical success factors

7. Recording a performance measures in a database

8. Selecting team-level performance measure 
9. Selecting organizational winning KPIs

10. Developing the reporting frameworks at all levels

11. Facilitate the use of winning KPIs

12. Refining KPIs to maintain their relevance

Together Higo grid and the 12-step model have been used to implement a successful performance Dashboard. The following paragraphs present the way these models have been applied to BT Italy context.

\section{BT scenario}

Since 1995, BT Italy has been a major provider in Italy of data, voice and internet services to corporate customers. Historically it has provided tailored solutions to its customers. Moreover it has been offering a wide product bouquet to create a high value proposition. The company organization reflected the effort to be closer to the customer with six business units facing different customer segments.

Several initiatives took place to improve business processes performance. Top Management had a punctual view of the business processes performance, such as Order Acquisition, Order delivery. Nevertheless, it wanted to enhance end-to-end view to take actions improving the customer experience and reducing the lead time. Therefore, supported by the consulting firm Business Integration Partners, BT Italy started a challenging reengineering project, namely "Eleven", that encompassed all the company and aimed to innovate the way services were delivered and monitored.

\section{The business performance monitoring model}

The project objective has been to build a model to monitor the performance of customer services business processes, such as from customer's service request to service delivery and bill. For that reason it was important to monitor both completed and work-in-progress orders. In this way management could not only analyze business process performance but also take timely actions impacting ongoing orders. Therefore, the model considers the following classes: Time, Quality, Volumes and Economics. The former two classes aim monitoring the lead time and the quality of each activity of the processes. The remaining two classes monitor the work-in-progress orders and the revenues on the Fiscal Year embedded into orders fulfilment. Time and quality classes are calculated for all completed order within a certain period of time. In this way it is possible to break an end-to-end lead time into the lead time of the activities which compose them. Indeed, Volumes and Economics classes are calculated for all work-in-progress orders at the maximum date of a certain period of time. Unlike HIGO, the model does not monitor the costs related to the process, mainly FTEs (Full Time Equivalent) and fixed costs, but the revenues immobilized into work-in-progress 
orders. By knowing the revenues on the fiscal year of these orders, the Top Management can better prioritize actions. Such as, pushing orders that worth the most.

As Parmenter recommends, the model aims giving both a high level and operational level views of the process performance. These depend on the user's level, which could be either a top manager or a process team member. Therefore, we have created a hierarchy of indicators allowing multi-level analysis ranging from the end-to-end process to the critical activities to be monitored.

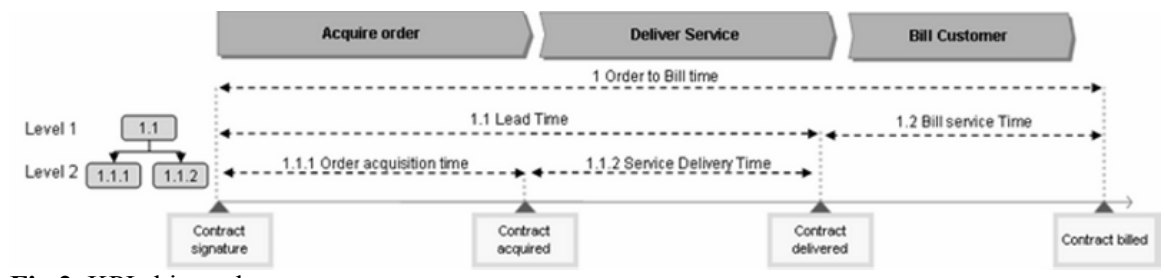

Fig.2. KPIs hierarchy

The figure above shows an example of hierarchy for KPIs of the class Time. The main process has been broken down into activities which are critical to the business performance. Each activity is uniquely associated to an organizational structure. In this way it is possible to measure each process player's contribution to the overall process performance.

Below are shown the drivers to select indicators:

- Relevance to the customer

- Relevance to the Top Management

- Availability of needed data to calculate the indicator. In this way it has been minimized the impact on the current IT systems of BT Italy.

The latter but not the least driver has been the feedback from future users. More than fifty one-to-one meetings were held to share the model with both the top management and the main team managers. The model considers the performance monitoring needs of different business unit directors. In this way it has gained a spread consensus.

The model includes a total of 68 indicators divided into three levels (18 are first level indicators). Below are shown some indicators:

Table.1. KPI

\begin{tabular}{|l|l|l|l|}
\hline Time & Quality & Volumes & Economics \\
\hline$\bullet$ Order to Bill & $\bullet \%$ of delivered & $\bullet$ \# of work-in- & $\bullet$ Total Revenues \\
time & orders without de- & progress orders & on the fiscal \\
& vear \\
$\bullet \%$ of & validation & \# of work-in- & progress-and-late \\
delivered-on- & $\bullet$ \# of de-validations \\
time orders & $\bullet$ \# undeliverable & orders & $\begin{array}{l}\text { Total revenues } \\
\text { on the FY on } \\
\text { process X }\end{array}$ \\
$\begin{array}{c}\text { Order to } \\
\text { delivery time }\end{array}$ & orders & & \\
\hline
\end{tabular}


The model adds further information to some indicators, such as aging, process phase, and responsibility. Therefore, the user can make specific orders' analysis. For example, work-in-progress orders that are more than 90 days late, revenues immobilized in orders of phase 1 or in undeliverable order due to client's responsibility. Since there are different processes depending on products category, there are indicators measuring the same performance but with different calculation formulas.

\section{The performance dashboard}

The objective was to provide a user friendly interface with the following features:

- Allowing at-first-sight performance analysis. Top managers wanted to have all information they need to figure out the process performance. This just in a web page without scrolling;

- Allowing targeted analysis. Users should be able to analyze process performance by measuring indicators for specific dimensions. Such has clients, products, etc;

- Supporting management decision making. Managers should be able to identify orders with the worst performance. Moreover they should know whom to contact to deal with;

- Allowing users to drill indicators down to specific orders or to the next hierarchical level.

Within a period of three months, a web-based application has been delivered. It allows measuring and monitoring the indicators defined on the model described above. The same sharing approach as for the model was applied. Therefore, the dashboard is a result of several one-to-one meetings with directors and process owners. There are no access profiles. So, all users from different business units see the same indicators. Hence, every manager is aware of the contribution to the overall process.

The dashboard home page has four sections, one for each performance class indicator. The sections fit into the PC screen without scrolling. Also it shows the relevant indicators and other information, such as trends, to monitor process performance. To make the monitoring as visual as possible, we used objects such as tachymeter and charts, mainly bar and pie charts. Tachymeters have red or green areas. By looking at the area colour, the user can immediately understand whether the performance is negative or positive. Others indicators are represented with charts. For example, volumes of work-in-progress orders are represented trough a pie chart. Its slices show the volumes of the three main sub-process of the Order To Bill process. In this way user can immediately understand which the overloaded sub-process is.

To facilitate performance analysis and decision making, all these objects are mouse-scroll-over sensitive. By clicking on a specific bar or pie slice, the user can open a report showing only orders behind the selected object part. In this way, 
users can immediately focus their analysis on specific indicators value. For example, they can monitor the aging of late orders (which is represented by a bar charts with 5 age ranges) and analyze orders that are more the 90 days late.

The way users can see indicators and drill them down to next indicator's hierarchy it is similar to web site navigation. At the head of each page there is a bar with all the dimensions that the user can select to make a targeted analysis. Every time it is possible to visualize selected indicators filtering by one or more dimensions. To meet different business unit directors' needs without creating different profiles, the following analysis dimensions have been implemented: period of time (from, to), client, product name, product category, order type (new, modify, etc), business unit. For example, business unit director can monitor the performance of its business unit by selecting it by a drop-down list.

The selected software to develop the dashboard has been Pentaho suite, which is an open source application. It better fits all the project needs that can be summarized by the following drivers:

- Low license costs. It has no license costs.

- Low impact on current systems architecture. It does not need a complex integration with source systems.

- Availability of "off the shelf" features (reporting and KPIs analysis). It has rich libraries of graphical objects and reports to better show indicators.

- Short Time to Delivery. The Dashboard has been delivered in three months including a tuning phase in which some new features had been added.

Below is represented the application architecture:

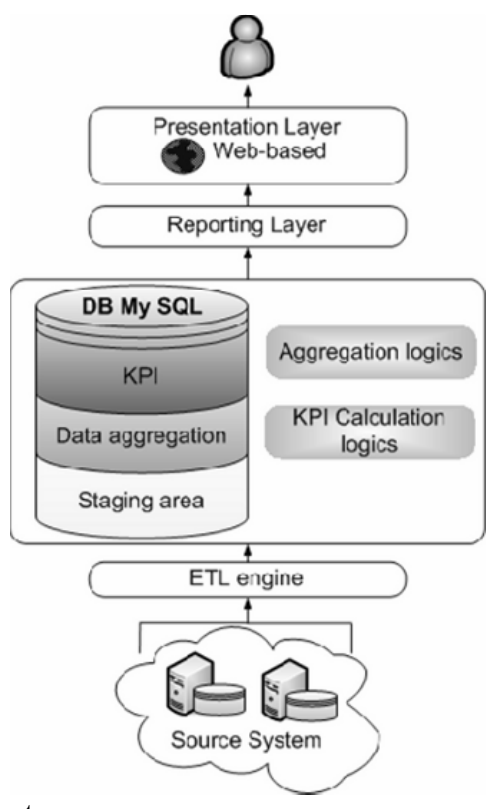

Fig. 3. Monitoring tool architecture 
The dashboard is integrated with two source systems. It receives data that are loaded by an ETL engine. An OLAP application calculates indicators that are shown through a web-based application, which is accessible within BT intranet.

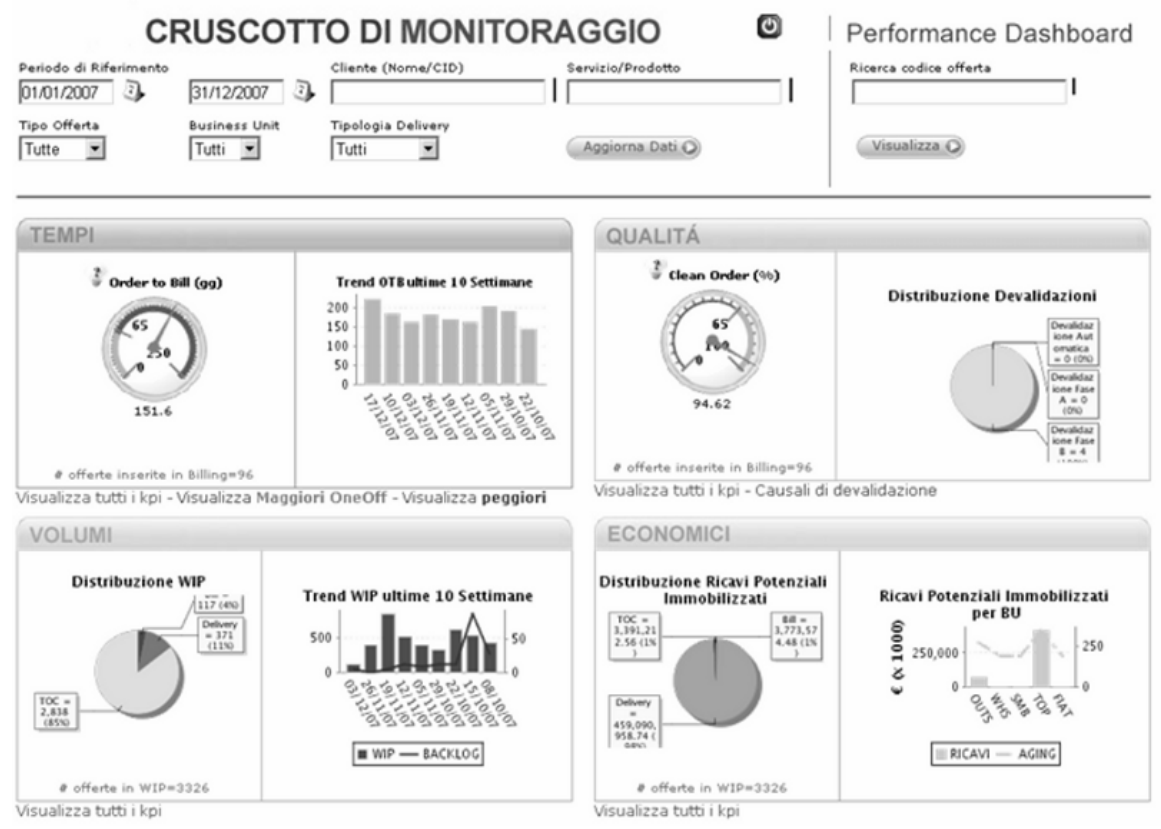

Fig. 4. Performance dashboard home page

The figure above shows the tool home page which allows monitoring the performance of the main indicators for each class.

\section{Conclusions}

HIGO framework had been useful to define and select KPIs to monitor business processes of BT Italy. By making some adjustments it has allowed the definition of several indicator which BT Italy is monitoring trough a user friendly interface. The deployed performance dashboard helps both top and operational managers to monitor performance and take day-by-day action to improve customer experience. In the future, BT Italy wishes to extend the performance monitoring to the moment the customer has the first touch point with BT and to the moment $\mathrm{BT}$ receives the payment from the customer. 


\section{References}

1. Inform-IT, Foundations of IT Service Management Based on ITIL ${ }^{\circledR}$ V3, Jayne Wilkinson, September 2007

2. Kaplan R. S., Norton D.P., Balanced Scorecard, Harvard Business School Press, Boston, Ma, 1996

3. Kaplan R. S., Norton D.P., The Balanced Scorecard - Measures that Drive Performance Kaplan e Norton, Harvard Business Review,1992

4. Longo A., Motta G., "Designing Business Process for sustainable performance: a model and a method", Business Process Design Workshop, 3d International Conference on Business Process Management, Nancy 5-7 September 2005

5. Motta G., "Il metodo dei KPI" in Bracchi G., Francalanci C., Sistemi Informativi e impresa digitale, McGrawHill, Milano 2005

6. Motta G., Pignatelli G., Competitività e sostenibilità dei processi gestionali, AICA, Milan, 2007

7. Parmenter D., Key Performance Indicators: Developing, Implementing, and Using Wining KPIs, John Wiley \& Sons, New Jersey, March 2007. 